http://jmscr.igmpublication.org/home/ ISSN (e)-2347-176x ISSN (p) 2455-0450

crossref DOI: https://dx.doi.org/10.18535/jmscr/v10i1.12

\author{
D) Journal Of Medical Science And Clinical Research \\ IGM Publication \\ An official Publication of IGM Publication
}

\title{
A Case of Azathioprine Induced Acute Pancreatitis in Post Renal Transplant Patient
}

\author{
Authors \\ Sanjeev Sharma, Roshini R, Reshma R
}

\begin{abstract}
Acute pancreatitis, the sudden inflammation of the pancreas is characterized by elevated levels of pancreatic enzymes such as amylase and lipase. Acute pancreatitis present as sudden onset of pain in the upper abdomen which may spread to the back side and vomiting. The most common cause of acute pancreatitis is gallstone, metabolic causes such as hypercalcemia, hypertriglyceridemia, infections and the drugs such asthiopurine (azathioprine, 6-mercaptopurine (6-MP)), corticosteroid, metronidazole and biological agents. Among them azathioprine mainly causes acute pancreatitis. Here we present a case on azathioprine induced acute pancreatitis.
\end{abstract}

\section{Introduction}

About $1-5 \%$ of the patients after organ transplantation suffers from acute pancreatitis. ${ }^{1}$ The common etiological factors in post renal transplant patients include biliary tract disease, alcohol intake, viral infection, hypercalcemia, hyperparathyroidism, hypertriglyceridemia, uremia, hypertension and drugs. ${ }^{2}$ Drugs such as thiopurine (azathioprine, 6mercaptopurine [6-MP]), corticosteroid, metronidazole and biological agents can lead to acute pancreatitis. A purine analogue, Azathioprine is used as an immunosuppressant which prevent graft rejection of transplanted organ. $^{3}$

Acute pancreatitis is confirmed by any of the two criteria such as abdominal pain, serum amylase or lipase greater than three times the upper limit of normal and characteristic findings from abdominal imaging. ${ }^{4}$ The following criteria determine the drug induced acute pancreatitis: (1) The time sequence between the drug administration and acute pancreatitis development. (2) Improvement of clinical status after drug withdrawal. (3) There is re-appearance of symptoms, after re-exposure. ${ }^{5}$ Management of acute pancreatitis include Intravenous fluid resuscitation which is titrated according to urine output and comorbidities of patient, electrolyte replacement, analgesia and treatment of underlying causes and complications of acute pancreatitis. Withdrawal of drug is essential in case of suspected drug induced acute pancreatitis. ${ }^{6}$

\section{Case Report}

A 49-year-old post renal transplant female patient who presented to emergency department of our hospital with complaints of pain in the left hypochondric and epigastric region radiating to the back associated with 3-4 episodes of vomiting 
and one episode of loose stool. On physical examination she was conscious and oriented, Blood Pressure: 120/80 mmHg, Pulse:80 bpm, Respiratory rate: 20 breath per min, the abdomen was soft and no tenderness was present. She had undergone renal transplant surgery in 2020 and was taking Azathioprine $50 \mathrm{mg}$ twice a day for last two weeks. On laboratory tests, $\mathrm{Hb}: 12 \mathrm{~g} / \mathrm{dl}$, Total Leucocyte Count: 11690 c/cumm, platelet: 164000 c/cumm, Total RBC: 4.16 million c/cumm, CRP:217.86 mg/L, Hematocrit: $37.6 \%$, blood urea: $24 \mathrm{mg} / \mathrm{dl}$, serum creatinine: $0.9 \mathrm{mg} / \mathrm{dl}$, serum sodium: $146 \mathrm{mEq} / \mathrm{L}$, serum potassium: 3.5 $\mathrm{mEq} / \mathrm{L}$, serum calcium: $8.7 \mathrm{mg} / \mathrm{dl}$, serum chloride: $110 \mathrm{mEq} / \mathrm{L}$, serum phosphate: $3.9 \mathrm{mg} / \mathrm{dl}$, SGOT: 59 U/L, SGPT: 63 IU/L, ALP: 60 U/L, GGTP: $146 \mathrm{U} / \mathrm{L}$, total bilirubin: $1 \mathrm{mg} / \mathrm{dl}$, direct bilirubin:0.5 mg/dl, total protein: $5.8 \mathrm{~g} / \mathrm{dl}$, serum albumin: $4.1 \mathrm{~g} / \mathrm{dl}$, serum globulin: $2 \mathrm{~g} / \mathrm{dl}, \mathrm{A}: \mathrm{G}$ ratio: 1.9 , serum amylase: $3040 \mathrm{IU} / \mathrm{L}$, serum lipase: $5630 \mathrm{IU} / \mathrm{L}$, Non Contrast Computerized Tomography was performed which showed bulky pancreas with indistinct margins and peripancreatic fat stranding. USG abdomen and $\mathrm{x}$ ray abdomen shows no significant findings.

In view of above lab values the patient was diagnosed as acute pancreatitis and undergone supportive management. At the time of admission, patient was on Prednisolone $5 \mathrm{mg} /$ day, Azathioprine $100 \mathrm{mg} / \mathrm{day}$, Tacrolimus $3 \mathrm{mg} /$ day, Sulphamethoxazole/Trimethoprim $\quad 800 / 160$ $\mathrm{mg} /$ day. To control diabetes mellitus and hypertension, Linagliptin 5mg/day and Metoprolol $12.5 \mathrm{mg} /$ day were taken respectively. Work up for abdominal pain was done in which her amylase and lipase were found to be raised. Renal function and urine output was continuously monitored. By excluding the other causes of acute pancreatitis, drug induced acute pancreatitis was diagnosed. Causes such as gallbladder stone, alcohol, hypercalcemia, hypertriglyceridemia was ruled out in our patient. On the second day of hospital admission, drug azathioprine was discontinued as it is a major factor for inducing acute pancreatitis and started conservative management. From the third day onwards, we noticed improvement in the clinical status of the patient and hence we concluded it as a case on azathioprine induced acute pancreatitis. On the fourth day, symptoms such as pain and vomiting subsided with conservative management thereby patient's condition improved. Patient was discharged on the next day and called for follow up.

\section{Discussion}

Acute pancreatitis is the severe inflammatory clinical condition with high mortality of $1-30 \%$.In transplant patients, azathioprine may be implicated as amajor cause of drug induced acute pancreatitis. ${ }^{1}$ However, the exact mechanism of drugs induced acute pancreatitis is unknown. The cytotoxic effect of drugs that are caused by mechanisms such as biliary construction, accumulation of toxic metabolites and hypersensitivity, may be the reason for acute pancreatitis. From the literature reports, the risk of getting acute pancreatitis is eight times higher in patients taking azathioprine. ${ }^{7}$ Upon withdrawal of the offending drug, all the signs and symptoms disappear over a period of 1-11 days in case of drug induced acute pancreatitis, which is benign course whereas in post-transplant immunosuppressed patients it may be severe or lethal course. ${ }^{8,9,10}$ In our patient it took 3 days to recover from signs and symptoms. The incidence of pancreatitis is higher in post-transplant patients than non-transplant patients (20-30\%). The mortality in immunocompromised patients ranges from $50-100 \%$, whereas only $5-10 \%$ of mortality rate is in non-immunosuppressed patients. ${ }^{10-14}$ Our patient undergoes renal transplantation since one year and was on mycophenolate mofetil 360 mg twice a day. Later patient came in out-patient department and prescribed azathioprine $500 \mathrm{mg}$ twice a day. The diagnosis of drug induced acute pancreatitis is made by excluding other clinical causes. ${ }^{7}$ Causes such as gallbladder stone, alcohol, hypercalcemia, hypertriglyceridemia was ruled out in our patient. ${ }^{1,15}$ After two weeks of azathioprine administration, patient admitted with 
complaints of abdominal pain, vomiting and loose stool. Acute pancreatitis was detected after two weeks of azathioprine course, hence this drug was stopped on the second day of hospitalization and managed with conservative therapy.

In conclusion, patients with azathioprine induced acute pancreatitis, azathioprine is contraindicated and should not be used. In case if patient develops severe symptoms of acute pancreatitis, immediate medical care should be taken. Patients who are taking azathioprine should be closely monitored for the manifestations of acute pancreatitis, as azathioprine frequently causes acute pancreatitis. Rechallenge in our case could not be done as azathioprine is contraindicated in patient with azathioprine induced acute pancreatitis.

\section{Reference}

1. Siwach V, Bansal V, Kumar A, Rao Ch U, Sharma A, Minz M. Post-renal transplant azathioprine -induced pancreatitis. Nephrol Dial Transplant. 1999;14: 2495-2498.

2. Mallory A, Kern F Jr. Drug induced pancreatitis: A critical review. Gastro enterology 1980;78:813-820.

3. Fousekis FS, Theopistos VI, Katsanos KH, Christodoulou DK. Pancreatic involvement in inflammatory bowel disease: A review. J Clin Med Res. 2018; 10(10): 743-751.

4. Tenner S, Baillie J, DeWitt J, Vege SS. American College of Gastroeneterology Guideline: Management of Acute Pancreatitis. Am J Gastroenterol. 2013;108(9): 1400-1416.

5. Nitsche C, Maertin S, Scheiber J, Ritter CA, Lerch MM, Mayerle J. Drug-induced pancreatitis. Curr Gastroenterol Rep. 2012;14(2):131-138.

6. Nesvaderani $M$, Eslick GD, Cox MR. Acute pancreatitis: Update on management. Med J Aust. 2015;202(8): 420-423.
7. Floyd A, Pedersen L, Nielsen GL, Thorlacius-Ussing O, Sorensen HT. Risk of acute pancreatitis in users of azathioprine: a population-based casecontrol study. Am J Gastroenterol 2003; 98:1305-1308.

8. Haber CJ, Meltzer SJ, Present DH, Korelitz BI. Nature and course of pancreatitis caused by 6-mercaptopurine in the treatment of inflammatory bowel disease. Gastroenetrology1986; 91:982986.

9. Nogueira JR, Freedman MA. Acute pancreatitis as a complication of Imuran therapy in regional enteritis. Gastroenterology 1972;62(4): 1040-1041.

10. Slakey DP, Johnson CP, Czeperle DJ et al. Management of severe pancreatitis in renal transplant receipients. Ann Surg 1997;225: 217-222.

11. Fernandez-Cruz L, Targarona EM, Cugat E, Alcaraz A, Oppenheimer F. Acute pancreatitis after renal transplantation. $\mathrm{Br} \mathbf{J}$ Surg 1989;1132-1135.

12. Burnstein M, Salter D, Cardella C, Himal HS. Necrotizing Pancreatitis in renal transplant patient. Can J Surg. 1982; 25: 547-549.

13. Taft PM, Jones AC, Collins GM, Halasz NA. Acute pancreatitis following renal allotransplantation. A lethal complication. Dig Dis. 1978; 23:541-544.

14. Fernandez JA, Rosenberg JC. Post transplantation pancreatitis. SurgGynecol Obstet. 1976; 143:795-798.

15. Mallory A, Kern F Jr. Drug-induced pancreatitis: a critical review. Gastroenterology 1980;78:813-820. 